\title{
Erratum to: Convexity subarachnoid haemorrhage has a high risk of intracerebral haemorrhage in suspected cerebral amyloid angiopathy
}

\author{
D. Wilson ${ }^{1}$ - I. C. Hostettler ${ }^{1}$ - G. Ambler ${ }^{2}$ - G. Banerjee • H. R. Jäger $^{3}$ • \\ D. J. Werring ${ }^{1}$
}

Published online: 27 February 2017

(C) Springer-Verlag Berlin Heidelberg 2017

\section{Erratum to: J Neurol DOI 10.1007/s00415-017-8398-y}

The author would like to correct the errors in the publication of the original article. The corrected details are given below for your reading.

In "Discussion", first sentence of the fourth paragraph should read as:
The pooled event rate of $19 \%$ per year for future ICH in patients with probable CAA is higher than the future risk of recurrent ICH previously reported after ICH: $1.3-2.9 \%$ per year following deep ICH and 2.5-14.3\% per year following lobar ICH [33].

The online version of the original article can be found under doi:10.1007/s00415-017-8398-y.

D. J. Werring

d.werring@ucl.ac.uk

1 Stroke Research Centre, UCL Institute of Neurology,

University College London, Russell Square House,

10-12 Russell Square, London WC1B 5EH, UK

2 Department of Statistical Science, UCL, London WC1E 6BT, UK

3 Neuroradiological Academic Unit, Department of Brain Repair and Rehabilitation, Institute of Neurology,

University College London, London, UK 